\title{
LET US NOW PRAISE FAMOUS GUITARS: PERSONAAND THE MATERIAL DISPLAYS OF POPULAR MUSIC MUSEUMS
}

\author{
ChARLES FAIRCHILD
}

\begin{abstract}
The study of popular music museums has expanded greatly in the past decade or so. The numerous studies produced so far have largely focused on issues to do with tourism, heritage, and curatorship. Most analysis has attempted to gauge the effectiveness and degree of success of the various methods of constructing and displaying collections of sounds, objects, and ideas. One area that can be of interest in moving beyond these analyses of museum practice is to examine how larger ideologies of artistry and artists that pervade the celebrity personas so assiduously built around famous musicians are an important foundation for these museums' displays. There are two reasons for the value of this approach. First, it should be clear that most exhibits in popular music museums are built to enhance, not contest already-existing images, historical narratives, and genre-defining attributes that surround well-known musicians. Therefore, it is not possible to understand these institutions without some sense of how they work with musician personas that necessarily precede any presentation in museum exhibitions. Second, we can see this dynamic in extraordinarily concise forms when we examine some of the 'famous objects' these museums display. We can often see an entire complex of received ideas about an artist encapsulated in just a few wellknown objects they once possessed. From this I will suggest that the personas of famous musicians that appear in most popular music museums do so through varied amalgams of symbolic and material forms meant to stabilise or enhance already-existing ideas about canonically-validated 'great' artists.
\end{abstract}

\section{KEY WORDS}

Popular Music Museums; Musical Celebrity; Popular Music Heritage

\section{INTRODUCTION}

Like most social history museums, popular music museums hang their reputations on both the quality and breadth of spectator experience and on the quality and breadth of their exhibitions and collections. Museums such as the Experience Music Project (EMP) in Seattle (now called the Museum of Popular Culture) or the Stax Museum in Memphis use high-profile objects in multiple ways at once to do this. These objects are legitimating presences for these institutions that demonstrate the quality and historical relevance of their collections, they act as marketing hooks to attract spectators, and they act as material, literal, and physical connections with the vanished past the exhibitions recount. Items such as the guitar on which Jimi Hendrix played The Star-Spangled Banner at Woodstock or some of the original instruments of Booker $\mathrm{T}$ and the MGs are important pieces that accomplish these goals. However, there is one thing these objects do that has a more resounding importance. Through their immediate presence, they act to confirm wider, farther-reaching historical narratives and ideologies of artistic value and 
aesthetic transcendence that are encapsulated by the personas of famous artists. By definition, these personas precede any museum exhibition about the artist and supersede any display of their possessions. My analysis shows that the personas of famous musicians that appear in most popular music museums do so through varied amalgams of symbolic and material forms meant to stabilise or enhance already-existing ideas about canonically validated "great" artists. From this, it should be clear that most exhibits in popular music museums are built to enhance, not contest, already-existing images, historical narratives, and genre-defining attributes that surround well-known musicians (see Fairchild 2018). I will use the exhibition of guitars in several popular music museums to explore these points and make the link between museum exhibits and expanded discourses of musical celebrity.

My interpretations of these exhibits will proceed from a few key ideas as to how their meanings are produced and shaped. First, each display is part of a much larger range of images and ideas about the artists in question. These images and ideas have long since been formed into coherent discourses of artistry and celebrity. Marshall's claims of what he calls "persona studies" are particularly relevant here. As he argues, new forms of celebrity are being produced through new forms of media and the distinct social relationships they foster. As such, he calls for "an investigation of this new constitution of the public and the private via a study of the formations of persona and the new forms in which the self is publicized" (Marshall 2014, p. 165). While Marshall's focus is on the emergent dynamics between traditional media forms and social media, we can also extend this investigation to include the ways in which the personas of musical celebrities are constructed historically. Importantly, this does not imply any kind of nostalgic separation of popular music museums from contemporary media forms that have proven capable of radically changing basic assumptions about the nature of the public and private experiences of celebrity. In fact, popular music museums play precisely on what Marshall identifies as the "the leaky nature of identity in celebrity culture" that is such a pronounced presence in contemporary popular culture. As he argues, this leakiness, in the form of "the gossip, the stories, the behind-the-scenes" revelations, produces complex versions of celebrity identity that move easily through both public and private arenas of social experience.

As I have argued elsewhere, popular music museums are very much a part of the culture of the so-called "new museum", which place a strong if not defining emphasis on capitalising on exactly the kinds of "leakiness" Marshall describes (Fairchild 2017). Music museum exhibits clearly use a wide range of often very personal stories and possessions to construct the kinds of "affective clusters" that "coalesce around stars" through an often careful blend of the intimate and the broadly historical. The displays of guitars examined here are precisely the sort of museum exhibits that seek to produce such affects. These displays are then used "by various industries for various commercial ends: the formation of audiences and selling of those audiences was the principal model of the commercial media and stars and celebrities were part of that construction of audiences" (Marshall 2014, p. 165-6). Most popular music museums are little different from other parts of the music industry in this regard. Their common goal is to produce musical subjects that are part of larger enfolding discourses of artistry and greatness.

Importantly, we need to understand how these museums do this by examining how they construct stardom as a relational process produced between artists and their audiences. As many scholars of celebrity have argued, it is difficult to understand celebrity without understanding the dynamic and evolving relationships between stars and fans (see Duffett 2014; Hills 2017; Stevenson 2009; York 2013). This relational model of celebrity is held together within these museums precisely by those familiar narratives of connection and intimacy most commonly present outside of them. In other words, in the exhibits examined here, audiences are present in these museums most often through continual appeals to the sorts 
of consensus versions of popular music history we find elsewhere in films, television shows, artist biographies and autobiographies. In the Jimi Hendrix and Johnny Cash examples in particular what I call their "consensus personas" provide a kind of baseline understanding of each of these musical celebrities on which the exhibits about them are based. "Great artists" and their "great art" are not presented in these exhibits to be contested or examined so much as confirmed and celebrated. These exhibits usually elide the role of these museums in reproducing and sustaining these consensus histories.

A second major area of concern we have to consider is the kinds of material display that are characteristic of music museums and how the specific materiality of their exhibits participate in the production of meaning about famous musicians. As Webb Keane has suggested, it is not sufficient to simply "read" objects symbolically as variously coded messages for museum-goers to simply decode. Instead, he argues we need to take account of the "unending process of signification", which is not defined by static, endlessly repeated meanings, but instead by the "sociability, struggle, historicity, and contingency" of the trajectory of such meanings (Keane 2005, p. 186). In other words, such meanings persist not simply through repetition, but through very particular modes of meaning-making that exceed the capacity of the literal or immediate qualities an object may possess. This understanding can allow us to attend to the dynamic ongoing relationships between the qualities of the objects on display and their relationship to the musician personas they evoke and recall. Webb argues that an object's most obvious qualities are always bound up with other qualities, some less obvious, some not visible or material at all. He calls this "bundling." No one quality can, Keane suggests, become apparent "without some embodiment that inescapably binds it to some other qualities as well, which can become contingent but real factors in its social life" (188). While we can use Keane's ideas to link the identity of disparate objects that all possess similar, bundled qualities, we can also use them to understand how very similar objects can embody very disparate qualities depending on how they are attached to those who once owned or used them. From this we will be able to recognise how "[a]bstracting qualities from objects offers a way to bring discrete moments of experience into an overarching value system on the basis of habits and intuitions rather than rules and cognition" (188).

I will do this here by analysing the display of a range of guitars at the EMP in Seattle and the Country Music Hall of Fame and Museum and the Johnny Cash Museum, both in Nashville. The overarching value system into which these now muted musical objects are enlisted are exactly those larger discourses of musical celebrity that both establish and sustain socially constructed and maintained ideas of artistic greatness.

This article is part of a larger project about music museums and their role in a symbolic representation system of music history and artistic celebrity made manifest through their displays. I have undertaken observational work at nineteen music museums in the US and the UK, collecting several thousand images of the museums, their settings and their exhibits, as well as an extensive collection of tourism documents (maps, brochures, guidebooks, etc.) all of which form the primary texts for my analysis. The overarching goal of this project is to track various ideologies of artistry, renown, and celebrity in these museums. My primary interests are in the museums themselves, the political economies that produced them, the characteristic attributes of their exhibits and historical narratives, and how all of these have been definitively shaped by ideologies that stretch well beyond these fairly immediate concerns. This project departs from general focus of the recent burst of work on popular music heritage in that I am not focused on the extent to which these museums are specific types of curatorial enterprises. Most scholarly work on them has been aimed at measuring the extent to which these institutions are successful in establishing popular music heritage as a legitimate endeavour (Baker et al. 2016; Brandellero 
\& Janssen 2014; Leonard 2014). Instead, I am trying to explore how the myths and stories of greatness and stardom pervasively present in these museums are produced, sustained, and made continually meaningful in a larger cultural economy. Here, I am examining how the symbolic resonances of guitars, posited as both tangible objects and intangible links to specific artists, are used to do this.

\section{THE QuALITIES OF GUTTARS}

In popular music museums, guitars are used in a wide variety of ways. First, they are potent symbols used to commemorate the passing of eras and artists. At the Beatles' Story Museum in Liverpool, for example, the main exhibit both begins and ends with guitars once used by John Lennon. The first is ambiguously posited as the very one he (may have) used at the famous Woolton School Fete, the last sitting somewhat forlornly in a large empty space next to the white piano he used to perform "Imagine." There are many similar guitars spread across many comparable museums, including those that once belonged to figures such as Ike Turner, Hank Williams, Maybelle Carter and Elvis Presley. These instruments are unique and most often used to tell a singular story. Second, other guitars, owned and played by less luminous stars and unique in similar ways, are instead used to narrate the wider social history of popular music. Figures such as Wanda Jackson and J. Mascis, for example, simply do not loom quite as large in the wider perception of the history of popular music. As such, their guitars do not provide quite the same material presence as many of the guitars of more famous artists. Instead, these less famous instruments are enlisted to fill out a few telling details of what are mostly familiar stories. They are presented to us as important and valued objects in glass cases, worthy of preservation for what they are presumed to be able to tell us about the past. Third, the image of the guitar is no less important to the experiences these institutions provide to spectators, and images of guitars abound. They appear in old publicity photos of the artists whose life and work these places chronicle. They appear in candid shots of everyday life from the distant past. We are initiated into the main exhibit of the Country Music Museum and Hall of Fame, for example, by an image of an old man sitting on a dilapidated front porch strumming an acoustic guitar. Similarly, as we pass by images of the homes of both black and white sharecroppers in the Memphis Rock and Soul Museum, we see instruments set in places of esteem in their respective homes. And, of course, guitars appear in the advertisements and tourism guides these museums use to attract spectators.

Like the personas of their often-famous users, a few key ideologies about the guitar as an instrument necessarily precede any of the museum exhibits about them and definitively shape the tenor and limits of those exhibits. The central qualities attributed to famous guitars are present in the texts and images surrounding these instruments, which more or less explicitly play on what spectators might already be expected to know about them. From these exhibits, it seems clear that we are expected to place the electric guitar in a larger discourse that posits the instrument as a symbol of power and rebellion that has long acted as a witness to, if not venue for, social change (see Ostburg \& Hartmann 2015). More broadly, guitars, especially electric ones, are often spoken about by their advocates as "real" instruments possessed of a certain innate weight of authenticity. Unlike those mysterious black boxes that produce beats and faux strings or horns, there is a certain apparent or perceived transparency about how guitars and guitarists make sound (Carfoot 2006, p. 35-6). As Carfoot explains, such perceptions are a part of a "range of actively produced...culturally constructed ideologies around the instrument" (36).

This article demonstrates how several displays of a few particularly famous guitars evoke wider perceptions and assumptions of those many indispensable ingredients of rock 
authenticity. These instruments are redolent of a certain brand of directness and immediacy that characterise the artistic achievements of their owners. Notably, very few of these exhibits talk about the actual sounds these instruments once made as sounds. Instead, they are used as vibrant props in a larger story of artistic achievement. A few examples can show us very clearly the kinds of implicit frames these museums employ when displaying such instruments. From these we can distil a typical way of displaying guitars.

We will start with the EMP's Guitar Gallery, a rotating exhibit of guitars from the museum's collection that can help us avoid a good deal of the rhetoric about greatness and timelessness that often accompanies exhibits in popular music museums. Instead, we can focus as closely as possible on how these guitars are presented as guitars. Indeed, many of the more famous objects in the EMP's collection are guitars owned by the museum's founder, the late Paul Allen, who was a passionate collector of the instrument. The frames these displays produce very often implicitly construct the guitar as a stereotypically "male" instrument defined by its seemingly inherent qualities of power and loudness, qualities in keeping with a long history of extolling such virtues in rock (see Weinstein 2013; Fast 1999; Waksman 1999). As Reitsamer (2018) argues, this is of a piece with the broader "gendered narratives" of popular music, and especially rock, in that "the formulation of a history of rock and specific criteria for attributing historical importance to performers which reinforced a definition of rock as a male art" (p. 26). Indeed, as Adelt (2017) shows, these institutions are very broadly reflective of existing gender and racial hierarchies in their collections and exhibits. Further, these instruments are presented as representative of retrospective validation of the music produced on them. Instead of presenting a malleable, or even labile, tool of endlessly variable musical expression, many of the EMP's most famous guitars are presented in a context that seems to suggest that what was once played on them was in some ways historically inevitable. As I note elsewhere, this sense of retrospective inevitability is present in popular music museums more broadly (Fairchild 2017, 2018).

As I have also noted elsewhere, the EMP's Guitar Gallery sets a wide range of individual instruments within a larger narrative of triumphal American exceptionalism. The gallery hails the innovative inventors and artists who were said to have permanently changed popular music (Fairchild 2017, p. 93-4). Many of the guitars are presented as "signature guitars," each linked to their equally unique owners. For example, the collection boasts one of four Gretsch custom rectangular-bodied electric guitars made for Bo Diddley in the early 1960s. The accompanying text notes that the instrument was based on a design Diddley came up with in 1945 as a teenager while attending the Foster Vocational School in Chicago. Nearby, we find a light blue Fender mustang that once belonged to Kurt Cobain and used on the 1993-4 In Utero tour. It, too, was altered for use, in this case by Nirvana's guitar technician, at Cobain's instruction. Both guitars are framed through the qualities instilled in them by their users. The Guitar Gallery has also displayed many other visually iconic guitars such as Gene Simmons' starburst design and Eddie Van Halen's black-, red-, and white-striped guitar, one that Van Halen famously made himself.

Despite the assertions of curators and scholars suggesting that the Guitar Gallery really is about the instrument itself, it remains very difficult to detach these famous instruments from their owners (see Adelt 2017; Baker, Istvandity \& Nowak 2016). This is especially true of those guitars specifically contextualised through their owners' biographies and those that still bear the marks of wear and use that indelibly stain them. What the Guitar Gallery shows us, beyond the instruments themselves, is a kind of generic or default way of exhibiting guitars by implicitly and explicitly linking their material qualities to the more widely known and available persona of their famous musician owners. Each instrument is displayed in a way that highlights its visual 
distinctiveness. The lighting is low throughout the gallery and each instrument sits silently in its own warm pool of light. Each is contextualised to contribute to the wider narrative of innovation and exceptional artistic success. The museum owns more than three hundred such guitars and rotates them through this gallery, displaying about 50 at a time to act, in sum, as a kind of proxy hall of fame. Each instrument is materially expressive of the history of its user, as most reveal the marks and stains made on them by their famous owners and are redolent of the many famous and important performances in which both guitarist and guitar were central actors. Each display supports the larger narrative conceits of the gallery as a whole, showing spectators the iconic tools used by musicians, who are themselves similarly iconic. This is characteristic of these kinds of exhibits, as the musicians and their instrument subtly become part of the same larger idea. The surrounding images and texts, some displaying the instruments in action, others indicating their sometimes unique design features, still others denoting the instruments' value and importance, all contribute to placing each in a sanctified space of remembrance. Importantly, any survey of exhibition types at most popular music museums will reveal very similar types of display.

We can expand on the forms of display presented by the Guitar Gallery to see how guitars fit into the broader narrative of particular traditions of popular music through similar forms of exhibition. As such, we need to understand how they are presented in conjunction with other objects, images and sounds, all of which combine to place these instruments in the context of whatever larger story a museum is telling. A good example is the main exhibit at the Country Music Hall of Fame and Museum. This exhibit is a massive sprawling display that occupies two full floors of a massive building and purports to tell the entire history of American country music. It proceeds mostly chronologically, but sets aside space for slight departures, such as a display case with a range of odd and unusual guitars, a display on the 1970s television show Hee Haw (the main attribute of which is a sizeable plot of fake corn stalks), and a massive wall of gold records. The bulk of the exhibit is dominated by a series of glass cases, most of which are about ten feet high and fifteen feet across, dedicated to a specific moment in history. Within each case is a collection of objects, images, and panels of text that highlight a distinct period in the history of American country music through the presentation of three or four members of the Hall of Fame. The Hall resides in a special room at the end of the exhibit. These artists are by definition "exemplary", as the life history of country music itself is folded seamlessly into the life histories of individual artists whose possessions make up most of the displays. These are the artists chosen by their peers and colleagues, and the museum itself, for admission into the Hall.

Two examples can show us a few distinctions in how guitars are used to tell the story the museum wants to tell. The first is a collection typical of the many large glass cases that dominate this exhibit. It is entitled "Settin' the Woods on Fire: New Sounds of the Jukebox" and is meant to sum up concisely a few developments in American country music in the 1930s. The main text tells us how "tough roadside nightspots forged an amplified steel-and-fiddle style known as honky tonk." This music was geared towards a younger rural population and "dealt with loss and spiritual dislocation, but also celebrated steppin' out on a Saturday night." This collection also incorporates the birth of bluegrass, music that often dealt with similar themes. The case displays instruments used by The Stanley Brothers in their bluegrass ensemble, a guitar once used by Kitty Wells, whose song It Wasn't God Who Made Honky Tonk Angels was the first ever number one for a female country artist, and Lefty Frizell's "Nudie Suit." A Nudie Suit is a personalised jacket and pants/skirt combination generously laced with sequins and rhinestones made by Nuta Koltlyarenko, professionally known as Nudie Cohn. The suits were a kind of sparkly rite of passage for emerging artists from the 1930s through to the 1980s. Most of the large cases in this exhibit, present both musical instruments and items of clothing to mark the importance of each member of the Hall of Fame. In each case, museum visitors are 
presented with highly personalised items, custom clothes and guitars, each of which marks the uniqueness of the artist and bears some direct trace of their passing through the world. These are strung together across the lengthy expanses of the exhibit to encompass what the museum frames as the entire social history of American country music.

The second example is a series of individual guitars played by such figures as Jimmy Rodgers, Maybelle Carter and Hank Williams donated to the museum. The first is Rodgers' Martin 00-18 acoustic. This was the guitar the artist used to record at the legendary Bristol Sessions in 1927, which, the accompanying panel tells us, "marked a turning point in the history of country music." We can see clearly that "this plain-looking, but elegantly designed mahogany and spruce" instrument is worn away just below the sound hole, the direct result of Rodgers' strumming and picking. Maybelle Carter's Gibson L-5 is similarly worn. We are told that this model of guitar was designed to be louder than any other model then available and Carter used it to "revolutionize the role of the guitar, transforming the rhythm instrument into a distinctive lead voice." Also included is Hank Williams' Martin D-28, on which he created his "unsurpassed legacy as a country singer and songwriter." The panel points out how Williams' son, Hank Williams Jr, left the guitar as it was when it was given to him after his father's death, the scratches reflecting "the wear and tear of countless personal appearances made by the charismatic Williams, everywhere from nightclubs and outdoor concerts to national television." In these cases, there is a perfect and seamless unification of the social history of country music with the artists and the carefully preserved instruments they used to create pieces of that history. The presence and material specificity of these guitars speaks to the lived experiences of those who were there. Beyond the social history of popular music these guitars are enlisted to help recount, prominent artists are placed within these streams of history and their guitars help draw very personal accounts of them.

\section{OF GUITARS AND GUITARISTS}

The links between famous guitars and the personas of their owners appear in far more detail in exhibits dedicated to individual musicians. In two separate exhibits, dedicated to Jimi Hendrix and Johnny Cash, what we might call the "consensus persona" of each artist form the foundations of each display. Each exhibit proceeds without any apparent self-awareness of the constructed nature of these personas, both of which are clearly built on the extraordinary amount of mostly retrospective commentary dedicated to the artists' lives and work. Hendrix and Cash have both been the subject of numerous books, feature films, television programs, and documentaries, very few of which have departed from the established historical patterns described below. Interestingly, Cash himself was a central participant in the construction of his persona through his autobiographical writings and reflections. These strongly shape the tone and tenor of the collection and exhibits at the Johnny Cash Museum, which opened in Nashville in 2013. Each exhibit reflects the existing themes and priorities of the almost exclusively retrospective works that have constructed each artists' persona.

There are a few central attributes of Hendrix's consensus persona that should be noted before seeing how this persona is reflected in the EMP's exhibit. First and foremost, Hendrix is predominantly spoken of as a guitarist. Indeed, he is uniformly regarded as popular music's greatest guitarist, if the many "best of" lists that regularly appear in major music publications are any guide. Although he sang, wrote songs, and played bass routinely during his career, there is little question that his persona is indelibly linked to his instrument and the guitar is by far the instrument that defines him and his legacy. The story that has been told about Hendrix over and over is of how it was his use of the guitar that redeemed his early struggles in various backing bands and touring outfits and answered the questions that surrounded his ultimate status. It 
was the guitar and Hendrix's use of it that elevated him into the highest strata of the rock canon. To note just one turning point in the narrative of Hendrix's artistry, in a 1969 article from Rolling Stone, Sheila Weller describes noticing an old photo of Hendrix in "a fifties Coasters-type R\&B group; processed hair, metallic-threaded silk-lapel suits, shiny shoes." Hendrix responded to her obvious mirth by saying, "That's okay...I don't try to cover up the past; I'm not ashamed of it." He follows this by saying "I don't want to be a clown anymore. I don't want to be a rock and roll star." Instead, the balance of the piece describes an artist struggling to escape into his artistry and realise what was then, what was still, to be accomplished (quoted in Potash 1996, p. 24-5). This trajectory, from gigging musician to transcendent presence, is a consensus that reaches into the academic literature as well, with one of the most prominent scholars of the electric guitar carefully noting nearly precisely the same "truths" as those presented in the numerous popular biographies and evocations of his life and times that have continued for decades (Waksman 1999, p. 77; see also Roby \& Schreiber 2010; Potash 1996).

This consensus appears with particular clarity in the EMP's extensive rotating exhibition of Jimi Hendrix memorabilia that has been housed at the museum since its opening. Paul Allen's unparalleled collection of Hendrix memorabilia has been often said to be the catalyst for establishing the museum itself and there has always been a gallery dedicated to exhibiting it in various forms. The forms this exhibit has taken are varied, ranging from an initial "life story" iteration to later versions focusing on specific periods in the artist's life to those focusing on particular aspects of his specifically musical influence. Here we see in a very tangible way the historicity and contingency of the meanings of Hendrix's fame as expressed, in part, through the items he left behind. The exhibit I examined in 2011, called "Jimi Hendrix: An Evolution of Sound", fit retrospectively into this consensus persona. The exhibit was set in a gallery dominated by a so-called "Hendrix Life Map", which stretched across the lengthy back wall of the exhibition space. This wall consisted of text, images, objects, and video and audio stations visitors could trigger to watch or listen to studio recordings and live performances. The wall was divided into five periods that cut across Hendrix's life under the titles "Hendrix in Seattle," "Chitlin Circuit," "The Village," "Swinging London," and "The World Stage". To the right of this was a wall displaying several extremely large images of lyric sheets and several photos of Hendrix taken while he was writing the displayed lyrics. The front of the gallery consisted mostly of large double-sided glass cases with various famous objects in them, such as a drum kit used by Mitch Mitchell when he played with Hendrix, a psychedelic jumpsuit Hendrix wore on stage, and a blue velour suit in which Hendrix was famously photographed. As you walk in to the main room, there were several glass cases on the left that housed a series of Hendrix's guitars. The central area of the exhibition included several large padded seats with built-in listening stations.

The exhibition's larger narrative was supported through displays that highlighted the material qualities of all of its objects - including the guitars - through the use of lighting, text, groupings of other related objects, and extensive imagery. The presence and particular qualities of the guitars on display were central to the exhibit's story. Again, the life histories of the guitars and the guitarist are folded seamlessly into one another and into the bigger story the exhibit is designed to tell. As the EMP's chief curator noted, this particular iteration of the periodically changing Hendrix gallery was meant "to celebrate the creative power of Jimi Hendrix and how he has affected the fabric of popular music." It was also intended to enhance what the curator called the "undying aura [that] now surrounds Hendrix, placing him on the throne of a blazing pantheon of rock 'n' roll" (McMurray 2008, p. 6). The exhibit did this by using the five major periods it had divided Hendrix's life into and creating a materially rich historical arc that bent ineluctably towards the moment at Woodstock when Hendrix played The Star-Spangled Banner 
on the white Fender Stratocaster, the very one sitting in the last case in the row. It is worth exploring how the guitars contribute to this narrative.

There were five guitars in this exhibit, each one displayed to match a period in Hendrix's life as defined by the exhibit. The first, "Seattle Scene," presented a humble Sears Silvertone guitar that was owned by Hendrix's childhood friend, Joe Gray. The guitar was set in a case with photos from a performance of one of Hendrix's early bands, The Rockin' Kings, and photos from the Washington Junior High School yearbook with Gray and Hendrix's smiling faces highlighted. The text explains how Gray let Hendrix use the guitar as Hendrix did not have one of his own. Hendrix used the instrument to play with several different bands at clubs in Seattle's Central District. The guitar has a simple, unadorned, light brown body and a single pick up. It speaks to the humble origins of the figure who would eventually ascend to the "throne." The second is a black 1955 Les Paul Custom that Hendrix and band mate Larry Lee bought together in 1963 when both were playing with Bob Fisher and the Bonnevilles. The text explains that the instrument was used when Hendrix was playing the "Chitlin' Circuit," the nickname for the string of theatres, nightclubs, and other performance venues that employed African American artists in the era of Jim Crow segregation. It stretched across the American east, south and midwest and for many became synonymous with long gruelling tours and low pay. The guitar speaks to these circumstances in material form while the text tells us how it witnessed Hendrix's move from the backing bands of the deep south to the clubs of New York City's Greenwich Village, a moment of important and influential transition. The third instrument is a bass guitar, a Hagström eight-string that Hendrix played while performing and recording with Curtis Knight and The Squires. We are told that this period of immersion in this "nexus of jazz, folk, blues revival, and rock 'n' roll" proved to be a "formative influence on the evolution of Hendrix's sound." The fourth guitar display is actually two guitars presented in the same case. They can only be presented to us in fragments as Hendrix destroyed each during shows at the Saville Theatre and the Royal Albert Hall in London in 1967. He was said to have done so to commemorate his final shows in the UK before heading off to perform at the Monterey Pop Festival. Strikingly, he had written the lyrics to Love or Confusion on the back of one of the instruments, explaining that he regarded smashing the guitar as a sacrifice of something he loved for the greater good. The final guitar is perhaps the most famous of all, the white Fender Stratocaster on which he played his symbolically raucous version of The Star-Spangled Banner at Woodstock. This is an object that speaks to both the triumphs of Monterey, Woodstock, and the Isle of Wight, but also the fact of his death at a young age that has stalked those final performances ever since. The guitar hangs, through a trick of the light, as if suspended in midair in its display case. When read against the accompanying text, which speaks of new collaborators and new musical directions, the gleaming white of the body and blonde wood of the neck is suggestive of the unknown, unfinished music that would never make its way into the world.

As with the guitars in the EMP's Guitar Gallery, these have each been marked by their own specific material histories. However, unlike those guitars, these guitars are grounded firmly and organically in Hendrix's formal designation as a "great" artist. Indeed, the meaning and presence of each guitar grows from Hendrix's historical, and by definition, retrospective status. Each guitar is described almost as if it too witnessed the events and circumstances that linked it to the musician and now sits before us as mute witnesses to Hendrix's paths through the world. While these objects sit in fairly close proximity to many others, such as family photographs, clothes, and other personal effects, the guitars are different. They are more symbolically resonant. While the guitars are used to denote familiar points in the recounting of the life of a great artist, their humble origins, greatness forged in the cauldron of struggle and hard work, and the final realisation of the changes they wrought on the world, these guitars feel as if they 
speak to a part of the artist's familiar persona in a different way. They seem to speak as a proxy for Hendrix's actual presence in a way that is both publicly familiar and privately intimate. In this exhibits, it is impossible to imagine Hendrix without these instruments and we are never asked to do so.

We can find similar forms of display at The Johnny Cash Museum in Nashville, another biographical exhibit that bears many similarities to the Hendrix exhibit in Seattle. We should also briefly summarise Cash's consensus persona in order to frame this exhibit. Cash was unusually expressive in his life and his music about who he thought he was. His efforts at selffashioning were rich and numerous (see Edwards 2009). From his earliest hits, the narrative of Cash's life and career reflected struggles with a certain darkness, in the form of very public struggles with faith and addiction for example, but his narrative also included stories of redemption and transcending those manifestations of darkness. As Richard Goldstein wrote in Vogue in 1969,

When Johnny Cash sings a hymn, you get this very solitary search for grace...That's a kind of aloneness The Beatles never touch. It's something Bob Dylan is reaching for now, in the guise of simplicity. To Johnny Cash it's right out there, like a goddamn scar" (in Streissguth 2002, p. 89).

This "scar" has proved a persistent theme in Cash's biography. From recent academic work to popular essays to retrospective collections of historical writings about Cash, the themes of injury, healing, and redemption through faith, in his god and in his work, predominate (Edwards 2009; Hayes 2018; Streissguth 2002).

In the Cash Museum, we find that the life histories of the guitars on display are nestled quite closely with that of the artist. However, this museum is even more personal and, given the fact that it is a standalone institution, it creates a far more comprehensive and personal narrative for visitors to follow. The museum opened nearly a decade after Cash's death and benefited from the availability of a huge range of personal and professional items, including the expected array of musical instruments and stage clothes, but also non-musical items such as a sideboard and a dinner service from Cash's lake house in Hendersonville, Tennessee, which was his home from 1968 until his death. The exhibit is also framed at the start and the end by guitars. At the start is a mock-up of a stage set for Johnny Cash and the Tennessee Two, his first group. It is backed by a floor-to-ceiling image taken from the cover of the album "His Top Hits" from 1958. In front of the image is an approximation of the band's original set up. On the left is guitarist Luther Perkins' small amp with a guitar case behind it and a Fender Esquire electric to the right. In the centre of the slightly raised stage area is a larger Fender amp and Johnny Cash's Martin acoustic, to the right stands an acoustic upright bass. Two aspects of this scene suggest its underlying purpose. First, there are two signs on the stage that were handwritten by Cash himself, both noting the provenance of the guitar and the small guitar amp. In the case of the amp, the note tells us: "On this amp was recorded Hey Porter, Folsom Prison Blues, I Walk the Line and others." The other reads: "My first 'professional' guitar. 1955-56." Second, the curators have threaded a dollar bill through the strings on the acoustic guitar, a trick Cash used to help get the famed, percussive 'Boom-chicka-boom' sound the band often produced. Here the museum uses the handwritten notes and the dollar bill to provide traces of the artist for the visitor, signalling this is a very personal exhibit.

There are several guitars set in larger panels that chronicle Cash's life. The first is part of a larger panel called "Life in Dyess," the Arkansas town where Cash spent most of his childhood. The panel contains a battery-powered radio ordered from the Sears and Roebuck catalogue, an acoustic guitar, also from the Sears catalogue, both of which are described as the same type and 
model as those owned by the Cash family, though not the actual ones they owned. These are placed in their own cases, which are surrounded by several images taken from family photos that form a kind of collage around other smaller items such as Cash's birth certificate, marbles Cash played with as a boy, and his high school yearbook from his junior year where he is described as "J.R. Cash, Droll." Similarly structured panels are repeated in this part of the museum, with one devoted to Cash's time in the air force, another describing the shows he performed at various prisons, and two that give broad overviews of the various episodes in the early part of his career. The two guitars that appear in these displays are notable for their personalisation. The first is also set in its own lit-up case. It is a Gibson J-200 acoustic model with a warm red body with a wide black playing area. The instrument was designed especially for Cash in 1959 and he used it in performances and recording sessions, but just as importantly in publicity photos, one of which forms the back panel of the case. The curvy script spelling out the artist's name on the front face of the neck acts as confirmation of the singer's increased status. The museum highlights this by including a handwritten lyric sheet for Cash's first number one hit, I Walk the Line, written long after the fact, that was given to the museum's founder and placed in the case with the instrument. Several subsequent cases include similar guitars, each symbolizing a different era in Cash's long career. The famous Cash-designed Grammer Guitar, played routinely on the short-lived "The Johnny Cash Show" sits in one, and a custom Martin with complex mother of pearl inlay on the neck and body (also designed by Cash) sits in another. Another guitar is signed by all four members of The Highwaymen. This so-called country "supergroup" was formed in 1985 and was comprised by Cash, Willie Nelson, Kris Kristofferson, and Waylon Jennings.

While each guitar adds a certain material heft to the chronicle presented to visitors, the last item in the museum is perhaps the most poignant. It is another custom Martin acoustic, also in its own lit-up case. It is a jet black Johnny Cash Signature Model, D42 from 1997. Cash also designed this instrument, of which fewer than 150 were produced. This guitar was used to record many of Cash's final recordings on the American Recordings series, a series of six studio albums recorded between 1994 and 2010, the final two released posthumously. The series brought Cash more high-profile praise and success than he had had in over a decade. His recording of songs such as Hurt by Nine Inch Nails, Personal Jesus by Depeche Mode, and The Mercy Seat by Nick Cave surprised and engaged a much younger audience than he had been used to in many years. These albums, recorded in a starkly minimal fashion, mostly with only limited accompaniment, became very publicly associated with a rapid decline in his health from 1997 and his eventual death in 2003. This particular guitar appears in his much-lauded video for Hurt. The museum explicitly links these recordings to Cash's long-standing, but often conflicted religious beliefs. The final panel of the museum explains at some length how Cash was raised "in a God-fearing family as a Southern Baptist" and while he "struggled with the temptations throughout his life...he never turned his back on his faith of God." Cash recorded gospel songs throughout his life and "earn[ed] an associate's degree in theology from the Christian International University." The text in this display ends with the following melancholy notation:

The last song Cash wrote was titled "My Lord Has Gone." He had taken the manuscript to the recording studio intending to come up with a melody to accompany his lyrics, but the session ended before he could accomplish his goal. He never returned to the studio, passing away on September 12, 2003.

The guitars displayed at the Johnny Cash Museum materially punctuate the chronicle of the artist's life in a manner similar to those in the Jimi Hendrix exhibit noted above. They support the overall narrative the museum's curators seek to establish, provide a very specific material 
focus for each panel of which they are a part, and have certain of their qualities highlighted through their own life history as well as the objects to which they are linked by proximity and by their contextualization in Cash's own life trajectory. In this case, the displays move from fairly generic guitars, bought by others for Cash to use, to carefully designed, custom instruments that become iconic objects in their own right. The displays repeatedly call the visitor's attention to the uniqueness of each through the accompanying text, imagery, and other objects that help fill out the story being told. This museum's story is one of the extraordinary longevity of Cash's career. The museum notes that Cash was one of the few recording artists to have recorded on formats that included "78, 45 and 33 1/3 RPM records, reel-to-reel audio tapes, 4-track and 8-track tapes, cassette tapes, CDs and Mp3 digital downloads". Notations such as these help to suggest, and later confirm, a story that tells us how Cash's life history took him from being a traditional commercial country singer playing on borrowed guitars to a globally recognised and respected recording artist whose life work continued right up until his final days. Within this story, we are also told of the many continuities despite the passage of time and the depredations of age, made visible through five carefully chosen images, one per decade of his career, that dominate the initial gallery. The latter galleries build on this theme with panels entitled "Writer", "Humanitarian", and "Artist", which describe Cash's activities beyond writing and performing music. In one sense, within the broad range of claims, stories, objects, images, video clips, and sound recordings, the guitars generally hold an equal status with other objects, such as the family radio, radio receiver and frequency meter of the type he would have used during his time in the military. They are narrative props of a sort, illustrative and demonstrative of the world as Cash knew and experienced it. But as with the Hendrix guitars, these instruments are special and especially intimate. The artist's hands were routinely placed on them and marked each of these instruments in visible ways. His use of them is confirmed not only through the marks on the guitars themselves, but through associated moving and still imagery. They stand in for the performances made with them and speak to those evanescent sounds that can no longer exist and they do so in ways few other objects in this museum can.

\section{CONCLUSION}

It might seem somewhat odd to focus so closely on the material and specifically non-soundproducing qualities of these instruments. But despite the fact that these museums produce a good deal of sound to surround visitors and shape their experiences of the objects and images displayed, offering much more on interactive kiosks and audio guides, none of these guitars are presented as sound-producing instruments. There are no audio recordings of them solely as guitars, but only as part of long-completed sound recordings or archival videos. There are only a few whose sound qualities are described in any detail at all. Such descriptions are almost always presented because the instrument is so unusual as to be an oddity or outlier. Instead, we are continually told that these are the instruments through which important things happened in the past, but we are rarely asked to focus only on the quality and character of the sounds they made. Instead, those sounds are almost always placed within the stories of the exemplary lives of the artists who made them. We are not asked to listen to specific sounds in quite the way we are asked to consider the specific moments when these instruments were brought to full musical life. This makes the physical presence and material qualities of these guitars that much more important, carrying far more weight in these exhibits than any distinct qualities their sounds may possess. This places these objects permanently in the past as, simply put, they will never make any sounds ever again.

Instead of simply being passive musical instruments, the guitars described above are central pieces of markedly personal narratives told through text, images, and objects 
constructing the "affective clusters" that "coalesce around stars" (Marshall 2014) in order to create the complex amalgam of the intimate and the historical on which the expressive dynamics of these exhibits turn. Also, while these instruments are central to the retelling of the artists' lives they represent, they are also part of larger sensory arrays of aural, visual and textual materials, without which these muted objects would be far less meaningful and symbolically resonant. In museums all over the world, spectators are asked to observe or engage with the material qualities of the personal belongings of famous people. They are often used as concise markers of larger stories, such as Virginia Woolf's eyeglasses or Beethoven's ear trumpets (Hancock 2010; Eckhardt 2008). The presence of these guitars stands in for familiar historical narratives and implicit ideologies of artistic value that are already embedded in the famous artist's persona. They are displayed in order to link visitors to what feels like a more immediate way to the artists who once owned and played them. These objects are marked, not just conceptually or symbolically through the accompanying stories, images and recordings, but also materially and tangibly through signs of wear or use. They are located in history and geography through accompanying text and imagery. And as such, they represent, indeed stand in for, an overarching value system defined by the consensus personas of the artists in question and by what are presumed to be already held beliefs about the value and meaning of their artistry. We can more readily imagine the artist's presence when we are in close proximity to the instruments through which they made their music and it is this presence these institutions so assiduously try to produce for their visitors.

\section{WORKS CITED}

Adelt, U 2017, 'Displaying the guitar: the rock and roll hall of fame and the museum of pop culture', Rock Music Studies, vol. 4, no. 3, pp. 207-220.

Baker, S, Istvandity L, \& Nowak R 2016, 'Curating popular music heritage: storytelling and narrative engagement in popular music museums and exhibitions', Museum Management and Curatorship, vol. 31, no. 4, pp. 369-385.

Brandellero, A \& Janssen S 2014, 'Popular music as cultural heritage: scoping out the field of practice', International Journal of Heritage Studies, vol. 20, no. 3, pp. 224-240.

Carfoot, G 2006 'Acoustic, electric and virtual noise: the cultural identity of the guitar' Leonardo Music Journal, vol. 16, pp. 35-39.

Duffett, M 2014 'Celebrity: the return of the repressed in fan studies?' in L Duits et al. (eds) The Ashgate Research Companion to Fan Cultures, Ashgate, Farnham, pp. 163-80.

Eckhardt, A 2008, The Beethoven-Haus Bonn, Verlag Beethoven-Haus Bonn, Bonn.

Edwards, L 2009 Johnny Cash and the Paradox of American Identity. Indiana University Press, Bloomington.

Fairchild, C 2018, 'Transcendent myths, mundane objects: setting the material scene in rock, soul, and country museums', International Journal of Heritage Studies, vol. 24, no. 5, pp. 477-490.

Fairchild, C 2017, 'Understanding the exhibitionary characteristics of popular music museums', Museum \& Society, vol. 15, no. 1, pp. 87-99.

Fast, S 1999, 'Rethinking issues of gender and sexuality in Led Zeppelin: A woman's view of pleasure and power in hard rock', American Music, vol. 17, no. 3, pp. 245-99.

Hancock, N 2010 'Virginia's Woolf's glasses: material encounters in the literary/artistic house museum', in S Dudley (ed.) Museum Materialities: Objects, Engagements, Interpretations, Routledge, London, pp. 114-27.

Hayes, J 2018 'He saw our darkness.' Bitter Southerner, retrieved 21 May 2019. https://bittersoutherner.com/ he-saw-our-darkness-johnny-cash-15th-deathanniversary

Hills, M 2017 'From fan culture/community to the fan world: possible pathways and ways of having done fandom', Palabra Clave, vol. 20, no. 4, pp. 856-83. 
Keane, W 2005 'Signs are not the garb of meaning: on the social analysis of material things', in D. Miller (ed.) Materiality, Duke University Press, Durham, pp. 182-205.

Leonard, M 2014 'Staging the Beatles: ephemerality, materiality and the production of authenticity in the museum', International Journal of Heritage Studies, vol. 20, no. 4, pp. 357-375.

Marshall, PD 2014 'Persona studies: mapping the proliferation of the public self', Journalism, vol. 15 , no. 2, pp. 153-170.

McMurray, J 2008 'Exhibition: Jimi Hendrix-an evolution of sound.' Imprint, Spring 2008, pp. 67.

Ostburg, J \& Hartmann B 2015, 'The electric guitar - marketplace icon', Consumption, Markets and Culture, vol. 18, no. 5, pp. 402-410.

Potash, C 1996, The Jimi Hendrix Companion: Three Decades of Commentary, Schirmer Books, New York.

Reitsamer, R 2018, 'Gendered narratives of popular music history and heritage', in S Baker, C Strong, L Istvandity \& Z Cantillon (eds), The Routledge Companion of Popular Music History and Heritage, Routledge, London, pp. 26-35.

Roby, S \& Schreiber B 2010, Becoming Jimi Hendrix: From Southern Crossroads to Psychedelic London, the Untold Story of a Musical Genius, Da Capo Press, New York.

Stevenson, N 2009, 'Talking to Bowie fans: masculinity, ambivalence and cultural citizenship', European Journal of Cultural Studies, vol. 12, no. 1, pp. 79-98.

Streissguth, M 2002, Ring of Fire: The Johnny Cash Reader, Da Capo Press, Cambridge.

Waksman, S 1999, 'Black sound, black body: Jimi Hendrix, the electric guitar, and the meanings of blackness', Popular Music \& Society, vol. 23, no. 1, pp. 75-113.

Weinstein, D 2013, 'Rock's guitar gods - avatars of the sixties', Archiv für Musikwissenschaft, vol.70, pp. 139-154.

York, L 2013, 'Star turn: the challenges of theorizing celebrity agency', The Journal of Popular Culture, vol. 46, no. 6, pp. 1330-47. 